\title{
Effects of 14 days of prophylactic resveratrol supplementation in trained endurance runners upon the inflammatory markers TNF-a, IL1 $\beta$, and IL-6 following a single bout of eccentric exercise
}

\author{
Fanny Dufour $^{1 *}$, Andrew White ${ }^{1}$, Stacie Urbina ${ }^{1}$, Lem W Taylor ${ }^{1,2}$, Colin D Wilborn ${ }^{1,2}$ \\ From International Society of Sports Nutrition: 8th Annual ISSN Conference and Expo \\ Las Vegas, NV, USA. 24-25 June 2011
}

\section{Background}

Resveratrolis a natural polyphenol found in peanuts and grapes. Resveratrolpossesses antioxidative properties which have shown to reduce the oxidative damage from reactive oxygen species (ROS). Resveratrol also has the ability to attenuate inflammation via inhibiting TNF-a, IL-1 $\beta$, IL-6, and blocking NF-kB activation. Resveratrol supplementation may have the potential to mitigate the damages associated with intense orprolonged exercise; consequently improving recovery. The purpose of this study is to evaluate the effects of a14 day prophylactic supplementation trans-resveratrol onTNF-a, IL-1 $\beta$, and IL-6 from a single bout of eccentric exercise in traineddistance runners.

\section{Methods}

Eight trained male distance runners ages 35 to 45 (38.13 \pm $2.95 \mathrm{yrs}$ ) were randomly assigned to consume in a double blind manner either a placebo (PL) or $1000 \mathrm{mg}$ of transresveratrol (polygonum cuspidatum)(RESV) daily for 14 days (Transmax, BiotiviaBioceuticals). Prior to supplementation participants' height $(69.5 \pm 2.3$ in $)$ and weight $(165.2 \pm 24.25$ lbs.) were recorded and body composition $(17.75 \pm 4.8 \mathrm{BF} \%)$ was assessed using DEXA. $\mathrm{VO}_{2} \max$ $(55.3 \pm 6.4 \mathrm{ml} / \mathrm{kg} / \mathrm{min})$ was assessed using Fox and Costill protocol and $65 \%$ of $\mathrm{VO}_{2}$ max heart rate $(117 \pm 4.2 \mathrm{bpm})$ was established for use as intensity predicator in the downhill running protocol. Following 14 days of prophylactic supplementation, participants engaged in a $45 \mathrm{~min}$ ute downhill running protocol at $65 \%$ of $\mathrm{VO}_{2}$ max at a declined grade of $12 \%$. Venous blood samples were taken prior to (PRE), immediately after(POST), one hour (1HR) and two hours (2HR) following the downhill protocol. Serum samples for each time point (PRE,POST, 1HR, $2 \mathrm{HR}$ ) were assayed for TNF-a, IL-1 $\beta$, and IL- 6 using ELISA. Dietary analyses were conducted during the four days prior to testing to determine any antioxidant and anti-inflammatory influences within the diet.

\section{Results}

A significant main effect for time $(\mathrm{p}=0.003)$ for IL-6 (RESV: $0.613 \pm 0.253,1.38 \pm 0.394,1.978 \pm 0.479,1.594 \pm 0.66$; PL: $0.921 \pm 0.73,2.25 \pm 1.05,1.698 \pm 0.561,1.953 \pm 1.87$ $\mathrm{pg} / \mathrm{mL}$ ). Delta responses for IL-6 showed a $125.12 \%$ change at POST, $222.68 \%$ change at $1 \mathrm{HR}$, and $160.03 \%$ at $2 \mathrm{HR}$ for the RESV group while the PL group showed a $144.3 \%, 84.36 \%$, and $112.05 \%$ change at the same time points, respectively. No significant observationsfor time or between groups for TNF-a and IL- $1 \beta$ were observed. Responsefrom baseline for TNF-a showed a $10.91 \%$ change at POST, $53.33 \%$ change at $1 \mathrm{HR}$, and $8.48 \%$ at $2 \mathrm{HR}$ for the RESV group while the PL group showed a $15.3 \%,-1.87 \%$, and $-8.96 \%$ change at the same time points ( $p>0.05)$, respectively. For IL-1 $\beta$, the response from baseline showed a $10.96 \%$ change at POST, $16.04 \%$ change at $1 \mathrm{HR}$, and $18.18 \%$ at $2 \mathrm{HR}$ for the RESV group while the PL group showed a $-39.67 \%,-31.15 \%$, and $-33.93 \%$ change at the same time points $(\mathrm{p}>0.05)$, respectively.No differences were observed on pain scale values between groups resulting from the eccentric protocol $(\mathrm{p}>0.05)$. 


\section{Conclusion}

The results of this study suggest that 14 days ofprophylactic Resveratrol supplementation does not attenuate inflammatory responses resulting from a single bout of eccentric exercise in trained endurance runners.

\section{Author details}

${ }^{1}$ Human Performance Laboratory, University of Mary Hardin-Baylor, Belton, TX 76513, USA. Exercise Biochemistry Laboratory, University of Mary Hardin-

Baylor, Belton, TX 76513, USA.

Published: 7 November 2011

doi:10.1186/1550-2783-8-S1-P15

Cite this article as: Dufour et al:: Effects of 14 days of prophylactic resveratrol supplementation in trained endurance runners upon the inflammatory markers TNF-a, IL1 $\beta$, and IL- 6 following a single bout of eccentric exercise. Journal of the International Society of Sports Nutrition 2011 8(Suppl 1):P15.

Submit your next manuscript to BioMed Central and take full advantage of:

- Convenient online submission

- Thorough peer review

- No space constraints or color figure charges

- Immediate publication on acceptance

- Inclusion in PubMed, CAS, Scopus and Google Scholar

- Research which is freely available for redistribution

Submit your manuscript at www.biomedcentral.com/submit 